\title{
Kinetics and Mechanism of the Aminolysis of Phenacyl Bromides in Acetonitrile. A Stepwise Mechanism with Bridged Transition State
}

\author{
Ikchoon Lee, Hai Whang Lec, and Young-Kab Yu \\ Department of Chemistr, Inha University, Inchon $402-751$. Korea \\ Recerved June 16.2003
}

\begin{abstract}
In the aminolysis of phenacyl bromides $\left(\mathrm{YC}_{6} \mathrm{H}_{4} \mathrm{COCH}_{2} \mathrm{Br}\right)$ with benzylamines $\left(\mathrm{XC}_{6} \mathrm{H}_{4} \mathrm{CH}_{2} \mathrm{NH}_{2}\right)$ in acetonitrile, the Brönsted $\beta_{\times}\left(\beta_{n+c}\right)$ values observed are rather low $\left(\beta_{\mathrm{N}}=0.69-0.73\right)$ ). These values are similar to those $\left(\beta_{\mathrm{X}} \cong 0.7\right)$ for other aminolysis reactions of phenacyl compounds with anilines and pyridines, but are much smaller than those $\left(\beta_{\mathrm{X}}=\mathrm{I}, 1-2.5\right)$ for the aminolysis of esters with benzylamines which are believed to proceed stepwise with rate-limiting expulsion of the leaving group. The relative constancy of the $\beta_{\mathrm{K}}$ values $\left(\beta_{\mathrm{K}}\right.$ $\cong 0.7$ ) irrespective of the amine, leaving group and solvent can be accounted for by a bridged type transition state in the rate-limiting expulsion of the leaving group. Thus the aminolysis of phenacyl derivatives are proposed to proceed stepwise through a 7 witterionic tetrahedral intermediate $\left(\mathrm{l}^{ \pm}\right)$, with rate-limiting expulsion of the leaving group from $\mathrm{T}=$. In the transition state, the amine is bridged between the carbonyl and $\alpha$-carbons, which leads to negligible effect of amine on the leaving group expulsion rate.
\end{abstract}

Key Words : Brönsted $\beta$ values, Aminolysis of phenacyl bromides, Stepwise mechanism, Cross-interaction constant

\section{Introduction}

The nucleophilic substitution reactions of phenacyl derivatives have attracted considerable attention of theoretical ${ }^{\prime}$ as well as experimental organic chemists. ${ }^{2}$ Nlthough a variety of mechanism has been proposed for the reaction by dillerent groups of authors, three types among them are considered to be worthy of note: (i) stepwise mechanism with a prior addition of the nucleophile (XN) to the carbonyl group, ${ }^{i}$, (ii) single step process with bridging of the nucleophile between the $\alpha$-carbon and the carbonyl carbon in the transition state (TS) , $1, b, 3\} .4_{2}$, and (iii) concented displacement with an enolate-like TS, 3 . Recently we<smiles>[3H]CC([N])([O-])CCC</smiles>

1<smiles>CCCCC1(CCC)C(=O)C1[Te]</smiles>

2

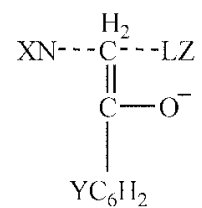

3 proposed a unified mechanism in which the reaction proceeds through an addition intermediate (1) with bridged type $\operatorname{TS}^{\prime \prime}(2)$ in the expulsion of the leaving group, $\mathrm{LZ}^{-}$. In the pyridinolysis of phenacyl bromides, the change in the $\beta_{\mathrm{X}}\left(-\beta_{\text {uuc }}\right)$ values from a large $\left(\beta_{\mathrm{X}}-0.7-0.8\right)$ to a small $\left(\beta_{\mathrm{X}} \cong\right.$ 0.4 ) at a breakpoint $\mathrm{p} K_{\mathrm{a}}^{\circ}-3.5$ in a biphasic Brönsted plot was observed providing evidence for the stepwise phenacyl transfer through a zwitterionic tetrahedral intermediate. $T$ : with rate-limiting expulsion of the leaving group. Another important piece of evidence for the slepwise mechanism was

"To whom correspondence should be addressed. Fax: +82-32865-4855; c-mail: ilec $a$ inha.ac.kr the positive cross-interaction constant $\rho_{X Y}(>0)$ in eq. 1 , where $X$ and $Y$ denote substituent in the nucleophile and substrate, respectively. It has been shown that in a stepwise

$$
\begin{gathered}
\log \left(k_{\mathrm{XY}} / k_{\mathrm{HH}}\right)-\rho_{\lambda} \sigma_{\mathrm{X}}-\rho_{Y} \sigma_{Y}+\rho_{\mathrm{XY}} \sigma_{\mathrm{X}} \sigma_{\mathrm{Y}} \\
\rho_{\mathrm{XY}}=\partial \rho_{\mathrm{Y}} / \partial \sigma_{\mathrm{Y}}=\partial \rho_{Y} / \partial \sigma_{\mathrm{Y}}
\end{gathered}
$$

carbonyl substitution mechanism with a rate-limiting breakdown of the intermediate, the sign of $\rho_{X Y}$ is positive? This is in contrast to negative $\rho_{\mathrm{XY}}$ values observed in the concered nucleophilc substitution reactions of benzyl, benzenesul fonyl and carbonyl compounds. ${ }^{8}$

In the present work, we extend our studies on the phenacyl transfer mechanism to the aminolysis of phenacyl bromides with benzylamines in acctonitrile, eq. 2 . The purpose of this work is to provide lurther evidence in support of our unified mechanism $(1+2)$ for the phenacyl transfier reactions.

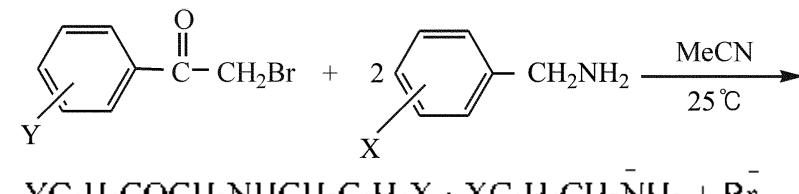

$\left.\left.\mathrm{YC}_{6} \mathrm{I}_{4} \mathrm{COCl}\right]_{2} \mathrm{~N}\right]\left[\mathrm{Cl}_{2} \mathrm{C}_{6} \mathrm{H}_{4} \mathrm{X} \cdot \mathrm{XC}_{6} \mathrm{Il}_{4} \mathrm{CI}_{2} \mathrm{NH}_{3}+\mathrm{Br}^{-}\right.$

$$
\begin{aligned}
& \mathrm{X}=4 \text {-OMe, 4-Me, } \mathrm{H}, 4-\mathrm{Cl} \text { or } 3-\mathrm{Cl} \\
& \mathrm{Y}=4-\mathrm{OMe}, 4-\mathrm{Me}, \mathrm{H}, 4-\mathrm{Cl} \text { or } 3-\mathrm{NO}_{2}
\end{aligned}
$$

\section{Results and Discussion}

The reactions followed the clean second-order rate law given by eqs. 3 and 4 , where $[\mathrm{BnA}]$ is the benzylamine

$$
\begin{gathered}
\mathrm{d}[\mathrm{Br}] / \mathrm{dt}=k_{0 h_{3} \mathrm{~d}}\left[\mathrm{YC}_{6} \mathrm{H}_{4} \mathrm{COCH}_{2} \mathrm{Br}\right] \\
k_{0 \mathrm{nlsh}}=k_{0}+k_{\mathrm{N}}[\mathrm{BnA}]
\end{gathered}
$$


Table 1. The Sccond-order rale constants, $k_{\wedge}\left(10^{-2} \mathrm{M}^{-1} \mathrm{~s}^{-1}\right)$, and selectivity paramelers for the reactions of Y-phenacyl bromides with $\mathrm{X}$-benzylamines in MeCX' at $25^{\circ} \mathrm{C}$

\begin{tabular}{|c|c|c|c|c|c|c|}
\hline \multirow{2}{*}{$\mathrm{X}$} & \multicolumn{5}{|c|}{ Y } & \multirow{2}{*}{$\rho_{Y}^{\prime \prime}$} \\
\hline & 4-OMe & 4-Me & II & $4-C 1$ & $3-\mathrm{NO}_{2}$ & \\
\hline 4-OMc & 9.55 & 10.8 & 12.8 & 15.8 & 26.6 & $0.45+0.01$ \\
\hline 4-Mc & 8.91 & 9.90 & 11.4 & 15.1 & 24.5 & $0.45+0.01$ \\
\hline $\mathrm{H}$ & 6.76 & 7.59 & 8.71 & 11.2 & 19.1 & $0.46+0.01$ \\
\hline $4-\mathrm{Cl}$ & 4.20 & 4.67 & 5.62 & 7.27 & 12.0 & $0.47+0.01$ \\
\hline $3-\mathrm{Cl}$ & 3.31 & 3.66 & 4.23 & 5.64 & 9.77 & $0.48+0.01$ \\
\hline$\rho^{\prime \prime}$ & $-0.75+0.05$ & $-0.76+0.04$ & $-0.76+0.03$ & $-0.73+0.05$ & $-0.7 I+0.04$ & $p_{\times} v^{r}=0.05$ \\
\hline$\beta Y^{c}$ & $0.73+0.06$ & $0.74+0.06$ & $0.74+0.05$ & $0.71+0.06$ & $0.69-0.05$ & \\
\hline
\end{tabular}

"The $\sigma$ values were taken from Henseb, C.: I.co, A.: Taft. R. W. Chent. Rev: 1991, 91. 165. The' $\beta_{X}$ values were determined using $p K_{4}$ values in water. The $\mathrm{K}_{0}$ values of benzy lamines in water al $25^{\circ} \mathrm{C}$ were taken from Blackwell. L. F.: Fischer. A.: Miller. J.: Topsom. R. D.: Vaughan. J. I. Chem. Soc 1964. 3588. The pKa 9.67 was used for 4-methoxy benzylarmine. "Correlation coelicients (1) are better tharn 0.993 . "r 0.991 . "t 0.999 (all). "r 0.994

concentration. The second-order rate constants $\left(k_{*}\right)$ were obtained as the slopes of plots of eq. 4 with more than five excess benzylamine concentrations. The $k$ v values are summarized in Table 1 together with the Hammett ( $\rho_{\mathrm{X}}$ and $\left.\rho_{Y}\right)$ and Brönsted $\left(\beta_{\mathrm{X}}\right)$ coefficient and cross-interaction constant, $\rho_{\mathrm{X}}$ : The $\beta_{\mathrm{K}}$ values determined by plotting $\log k_{\mathrm{N}}$ (MeCN) vs $\mathrm{pK}_{\mathrm{i}}\left(\mathrm{H}_{2} \mathrm{O}\right)$ in Figure 1 are considered reliable since the $\mathrm{p} K_{\text {il }}$ values in MeCN are linearly related with those in water with essentially a unity slope."

The $\beta_{\mathrm{X}}$ values in Table 1 are within narrow range of 0.69 0.73 , which are quite similar to those for other phenacyl transfer reactions. For example, the reactions of phenacyl benzenesulfonates $\left(\mathrm{YC}_{6} \mathrm{H}_{1} \mathrm{COCH}_{2} \mathrm{SO}_{2} \mathrm{C}_{6} \mathrm{H}_{1} \mathrm{Z}\right.$ where $\mathrm{Z}$ is a substituent in the leaving group) with benzylamines in $\mathrm{MeOH}$ gave $\beta_{X}$ values of $0.61-0.76^{16)}$ with $\rho_{X Y}-0.02-0.04$ and $\rho_{x}-0.09-0.12$. The $\beta_{\lambda}$ values for the reaction of $\alpha-$ chloroacetanilides $\left(\mathrm{YC}_{6} \mathrm{H}_{4} \mathrm{~N}(\mathrm{R}) \mathrm{COCH}_{2} \mathrm{Cl} ; \mathrm{R}-\mathrm{H}\right.$ and $\left.\mathrm{CH}_{3}\right)$ with benzylamines in DMSO were 0.56-0.87 ( $\left.\rho_{\mathrm{XY}}-0.2 \mathrm{l}\right)^{6 \mathrm{~b}}$ for $\mathrm{R}^{-} \mathrm{H}$ and $0.61-0.87\left(\rho_{\lambda Y}-0.18\right)$ for $\mathrm{R}^{-} \mathrm{CH}_{3}$. For the reactions of phenacyl benzenesulfonates with anilines in $\mathrm{MeOH}-\mathrm{MeCN}$ mixtures the $\beta_{\mathrm{X}}$ values obtained were $0.61-$ $0.76^{11}\left(\rho_{X Y}-0.05-0.14\right.$ and $\left.\rho_{X}-0.19-0.32\right)$. Likewise, for

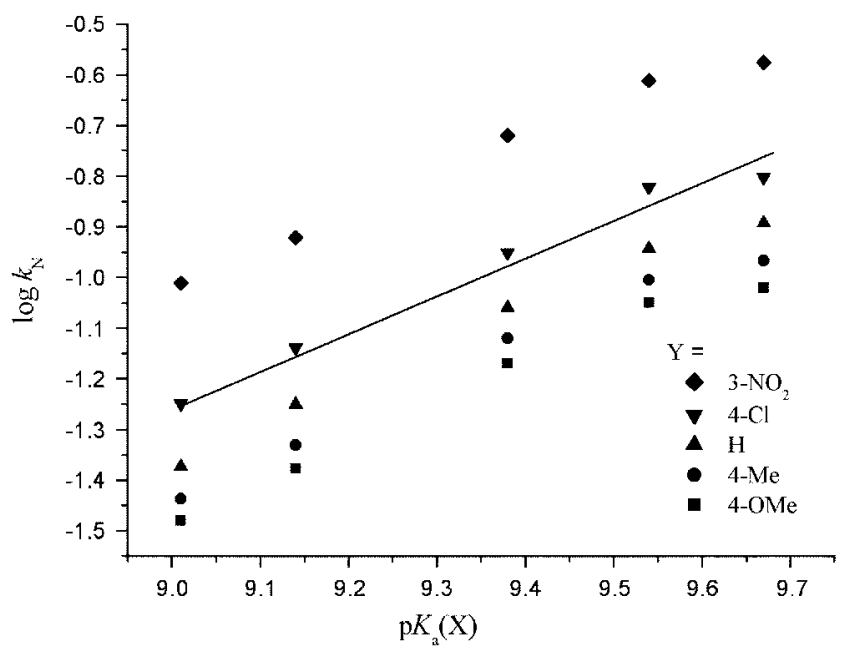

Figure 1. Brönsted plots for the reactions of Y-phenacy| bromides with $\mathrm{X}$-henzylamines in $\mathrm{MeCN}$ at $25^{\circ} \mathrm{C}$. the pyridinolysis of phenacyl bromides in $\mathrm{MeCN}$ the $\beta$. values were $0.65-0.78^{63}\left(\rho_{\mathrm{XY}}-1.36\right)$. All These phenacyl transfer reactions have nearly constant $\beta_{\mathrm{X}}$ values of $0.7+0.1$ and positive $\rho_{X Y}$ and $\rho_{X}$ values despite the fact that the phenacyl transfer reactions quoted above involve different nucleophiles, (benzylamines, anilines or pyridines), different leaving groups (benzenesulfonate, chloride or bromide) and different solvents $(\mathrm{MeOH}, \mathrm{MeCN}$ or DMSO). This is in quite contrast to the large difference in magnitude of the $\beta_{\mathrm{X}}$ values involved in the stepwise aminolysis of carbonyl and thiocarbonyl esters with rate-limiting expulsion of leaving group: aminolysis with benzylamines exhibited much larger $\beta_{\times}$values $(1.06-2.80)^{12}$ than those with anilines $(0.79-1.20)^{1.3}$ and/or pyridines $(0.64-0.94)^{14}$ in acetonitrile.

To rationalize the relative constancy of $\beta_{X}(\equiv 0.7)$ in the phenacyl transfers and the large differences in the magnitude of $\beta_{X}$ values between the stepwise aminolysis of esters with benzylamines (primary amines) and those with anilines and pyridines, we consider $\mathrm{MO}$ theoretical aspects of relative expulsion tate of the amine (NX) and leaving group (LZ) from the zwitterionic tetrahedral intermediate, $T^{\prime}$, involved in the stepwise aminolysis of carbonyl esters, eq. 5, where $X$. $Y$ and $Z$ represent substituents in the amine nucleophile, substrate and leaving group, respectively. The cationic product in eq. 5 undergoes deprotonation in a fast step when $\mathrm{NX}$ is primary or secondary amine.

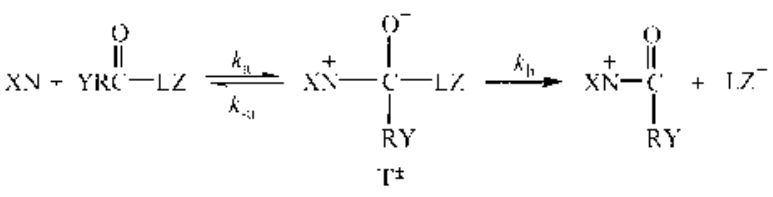

For the stepwise mechanisın with rate-limiting breakidown of $\mathrm{T}^{\prime}$ in eq. 5 , the overall rate constant $k_{\mathrm{N}}$ can be simplified as eq. 6 .

$$
k v-\left(k_{\mathrm{il}} / k_{-\mathrm{it}}\right) k_{\mathrm{l}_{1}}-K k_{\mathrm{b}}
$$

Thus, dependence of the rate $\left(\log k_{\Lambda}\right)$ on amine basicity $\left(\mathrm{p} K_{\mathrm{X}}\right)$ can be given as eqs. 7 . 


$$
\begin{aligned}
& \mathrm{d} \log k_{\mathrm{N}} / \mathrm{dp} K_{\mathrm{X}} \\
& =\mathrm{d} \log k_{\mathrm{a}} / \mathrm{dp} K_{\mathrm{X}}-\mathrm{d} \log k_{-\mathrm{a}} / \mathrm{dp} K_{\mathrm{X}}+\mathrm{d} \log k_{\mathrm{b}} / \mathrm{dp} K_{\mathrm{X}} \\
& \beta_{\mathrm{X}}=\beta_{\mathrm{a}}-\beta_{-\mathrm{a}}+\beta_{\mathrm{b}}
\end{aligned}
$$

Primary amines (e.g. benzylamines) will have strong localized cationic charge on the amine nitrogen $\left(-\mathrm{N}^{+} \mathrm{X}\right.$ in $\mathrm{T}^{\Rightarrow}$ ) whereas secondary and/or tertiary amines (e.g. pyridines) should have relatively weak positive charge on $-\mathrm{N}^{+} \mathrm{X}$ due to delocalization of the positive charge. ${ }^{15}$ In general. secondary and tertiary amines stabilize $\mathrm{T}^{-}$by delocalizing cationic charge on the amine nitrogen atom. ${ }^{15.16}$ The strength of the localized cationic charge will decrease therefore roughly in the order of decreasing rate of expulsion from

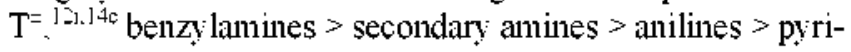
dines. Within a given series of amine. e.g.. substituted benzylamines or pyridines. an electron withdrawing substituent. $\delta \sigma_{\mathrm{x}}>0$. leads to a stronger localized cationic charge on $-\mathrm{N}^{-} \mathrm{X}$ in $\mathrm{T}^{-}$than an electron donating substituent. $\delta \sigma_{\mathrm{K}}<$ 0 . The cationic center on $\mathrm{N}$ constitutes a strong electron acceptor which will depress $\sigma^{*}$ level ${ }^{17}$ of the $\mathrm{C}-\mathrm{N}^{+}$bond orbital in $\mathrm{T}^{ \pm}$. The stronger the cationic charge the stronger is the electron accepting ability and hence the lower will become the $\sigma^{*}$ level. The depression of the $\sigma^{*}$ level. therefore. depends on the electron accepting ability of $-\mathrm{N}^{+} \mathrm{X}$ in $\mathrm{T}^{ \pm}$. not on the absolute basicity of NX. Thus the $\sigma^{*}$ level will be the lowest in $\mathrm{T}^{=}$with benzylamines and the highest with pyridines for the amine series considered above. This will in turn lead to the strongest vicinal charge transfer of the

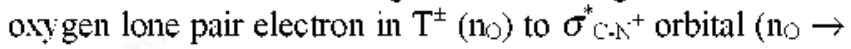
$\sigma^{*}\left(K^{+}\right)$for benzylamines since the second-order perturbation energy, $\Delta E^{2 j}{ }_{n \rightarrow \sigma^{*}}$. due to the charge transfer is inversely dependent on the energy gap. $\Delta \varepsilon=\varepsilon_{\sigma^{*}}-\varepsilon_{n}$. eq. $8^{17-1,5}$ where $\dot{F}_{n \sigma^{*}}$ is the Fock matrix element. $\left.F_{\mathrm{n} \sigma^{*}}=<\mathrm{n}|F| \sigma^{*}\right\rangle$. which is proportional to the overlap $\left(S_{n \sigma^{*}}\right)$ between the two

$$
\Delta E_{n \rightarrow \sigma^{*}}=-2\left(F_{n \sigma^{*}}\right)^{\hat{2} / \Delta \varepsilon}
$$

interacting orbitals. MO models of the intermediate show that the two lone pairs (no) on the oxygen atom are antiperiplanar ${ }^{15.9}$ to the two $\sigma^{*}$ bonds. $\sigma^{*} C . \mathrm{N}^{+}$and $\sigma^{*}$ C.LZ. which should give optimum $n_{\bigcirc} \rightarrow \sigma^{*}$ interactions ${ }^{18.19}$ as shown in Figure 2. The vicinal no $\rightarrow \sigma^{*}$ charge transfer interaction stabilizes $\left(\Delta E^{2)} \rightarrow \sigma^{*}<0\right)$ the intermediate. but weakens $\sigma^{*}$ bond and strengthens the bond in between the two interacting orbitals. ${ }^{19}$ Thus as the results of $n \rightarrow \sigma^{*}$ interactions. the $\mathrm{C}-\mathrm{N}^{-}$bond is weakened (easily broken and hence $k_{-a}$ is large) but the $\mathrm{C}-\mathrm{O}$ bond is strengthened (contracted) leading to a greater degree of double bond character for the carbonyl group $(\mathrm{C} \cdots \mathrm{O})$ and renders a larger negative charge on the carbonyl carbon.

In nucleophilic substitution reactions. effects of substituents in the nucleophile ( $\left.\sigma_{x}\right)$ and leaving group $\left(\sigma_{z}\right)$ on the progress of reaction (the TS position) along the reaction coordinate can be predicted using a model based on relative thermodynamic stability of products (or reactants) e.g. Hammond postulate. Bell-Evans-Polanyi principle etc. $21:=2$ These models predict that a substituent $\left(\delta \sigma_{\mathrm{K}}<0\right.$ and $/$ or $\delta \sigma_{\mathrm{Z}}$
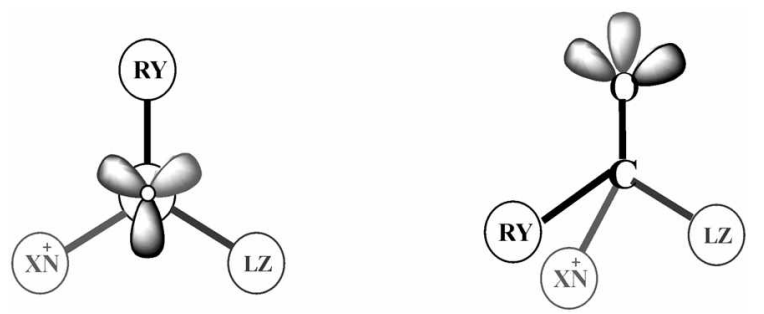

Figure 2. Antiperiplanar lone pairs on the oxygen atom to the three bonds, $C-N^{+} \mathrm{X}, \mathrm{C}-\mathrm{LZ}$ and $\mathrm{C}-\mathrm{RY}$, in a cuitterionic tetrahedral intenmediate, ' 1 '.

$>0$ ) which stabilizes product (and hence leads to a greater themodynamic driving force. $\delta \Delta G^{\circ}<0$. with a greater reactivity) results in an earlier TS with a smaller extent of bond making $\left(\delta \beta_{X}<0, \delta\left|\rho_{\mathrm{X}}\right|<0\right)$ and bond cleavage $\left(\delta\left|\beta_{Z}\right|\right.$ $<0 . \delta \rho_{z}<0$ ). Thus. a greater reactivity leads to a lower selectivity i.e. reactivity-selectivity principle ${ }^{2.3}$ (RSP) holds.

According to the principle of microscopic reversibility. ${ }^{2+}$ the TSs for the reversible steps. $k_{\mathrm{a}}$ and $k_{-\mathrm{d}}$. should be identical. Thus. the TSs for the two steps (one TS since $k_{a}$ and $k_{-a}$ have identical structure) can be represented schematically for benzylamines (stronger $n_{0} \rightarrow \sigma^{*}$ interaction leads to lager $k_{-4}$ with smaller negative $\beta_{-a}$ ) and pyridines (weaker $n_{0} \rightarrow \sigma^{*}$ interaction leads to smaller $k_{-4}$ with lager negative $\beta_{-4}$ ) as $\mathbf{4 a}$ and $\mathbf{4 b}$. respectively. These

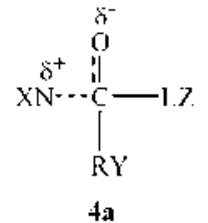

(later TS)

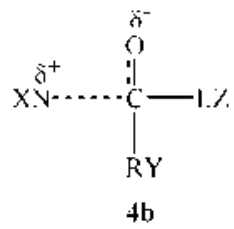

(carlicr TS) structures tell us that for the nucleophile with a strong cationic charge (4a) $\beta_{d}$ is large but $\beta_{-\mathrm{a}}$ is numerically small (small negative) since TS ta shows that bond fonmation has progressed to a large degree $\left(\beta_{\mathrm{a}}=\right.$ large positive) but expulsion of amine from $T^{-}$has progressed to a small degree $\left(\beta_{-a}=\right.$ small negative $)$. For the nucleophile with a weak cationic charge $(\mathbf{+ b})$ the situation is exactly opposite. i.e.. $\beta_{\text {s }}$ is small positive but $\beta_{-4}$ is large negative. In effect the two. $\beta_{4}$ and $\beta_{-\mathrm{s}}$ are complementany so that $\beta_{\mathrm{s}}-\beta_{-\mathrm{s}}$ portion of the $\beta_{\mathrm{x}}$ (eq. $7 \mathrm{~b}$ ) is practically constant. $\boldsymbol{\beta}_{\mathrm{s}}-\boldsymbol{\beta}_{\mathrm{a}} \equiv$ constant. irrespective of the amine nature. According to eq $7 \mathrm{~b}$ the nearly constant $\left(\beta_{\mathrm{a}}-\beta_{-\mathrm{a}}\right)$ is supplemented by $\beta_{\mathrm{b}}$, which means that the different size of overall $\beta_{\mathrm{X}}$ is primarily dependent on the $\beta_{0}(>0)$ value. The sign of $\beta_{0}\left(=d \log k_{b} / d p K x\right)$ is positive ${ }^{25}$ since for a given amine micleophile the expulsion rate of leaving group from $\mathrm{T}^{=}$increases $\left(\operatorname{dlog} k_{b}>0\right.$ ) with the basicity of amine (dp $\left.K_{X}>0\right){ }^{15}$ This is due to a greater push provided by a basic amine with the weak delocalized cationic charge on $-\mathrm{N}^{-} \mathrm{X}$ (and acyl group) ${ }^{15}$ in $\mathrm{T}^{=}$than by a weakly basic amine with the strong localized cationic charge on $-\mathrm{N}^{+} \mathrm{X}$. Conversely, a stronger localized cationic charge on $-\mathrm{N}^{-} \mathrm{X}$ in $\mathrm{T}^{ \pm}$exerts a stronger pull than a more delocalized 
cationic charge because of the greater electron demand. Thus a primary anine (e.g. benzylamine) with the strongly localized cationic charge in $\mathrm{T}^{-}$leads to the slower leaving group expulsion than a secondary or tertiary amine (e.g. pyridine) with delocalized cationic charge in $\mathrm{T}^{=}$. On the other hand. the greater $\beta_{\mathrm{x}}\left(=\beta_{\mathrm{a}}-\beta_{-\mathrm{a}}+\beta_{\mathrm{b}}\right.$ ) values for the aminolysis with benzylamines (5a) than with anilines and pyridines (5b) are resulted from the larger size of $\beta_{b}$ for benzylamines. This means that the rate of leaving group<smiles>[R]C([Y])([14CH3])[18OH]</smiles>

(later TS)

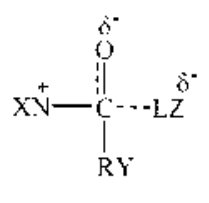

$5 \mathrm{~b}$

(carlier JS) expulsion from $\mathrm{T}^{-}$is small but selectivity is large for benzy lamine nucleoplile. The greater selectivity accompanying the lower reactivity is also evident in the observation that a greater degree of bond cleavage ( $\delta \rho_{z}>0$, greater selectivity) is obtained by a nucleophile with a stronger electron acceptor $\left(\delta \sigma_{\mathrm{Y}}>0\right.$ : weaker nucleophile) in the aminolysis of various esters. ${ }^{12-14}$ In these cases. $\rho_{Z}$ is the selectivity parameter representing susceptibility of the total rate (dlogk $\left.k_{\mathrm{N}}\right)$ to the substituent. $Z$, in the leaving group $\left(\delta \sigma_{\mathrm{Z}}\right)$. Adherence to the RSP is one of the criteria for the stepwise nucleophilic substitution of esters with rate-limiting breakdown of the tetrahedral intermediate. $T=7 b .26$

The correlation between $\sigma_{\mathrm{X}}\left(\partial \sigma_{\mathrm{X}}>0\right)$ and $\rho_{Z}\left(\partial \rho_{Z}>0\right)$ requires that the cross-interaction constant $\rho_{\mathrm{Nz}}\left(=\partial \rho_{\mathrm{Z}} / \partial \sigma_{\mathrm{X}}=\right.$ $\partial \rho_{\mathrm{N}} / \partial \sigma_{z}$ ) should be positive ${ }^{[(1.1] 1]^{12-14}}$ for the stepwise mechanism with rate-limiting breakdown of $\mathrm{T}^{-}$. By the same token. an increase in $\sigma_{\mathrm{X}}\left(\partial \sigma_{\mathrm{X}}>0\right)$ resulted in a larger positive $\rho_{\mathrm{Y}}\left(\partial \rho_{\mathrm{Y}}>0\right)$ value (Table 1$)$ with a stronger negative charge development on the carbonyl carbon. 611.11 .120 .139 .15 Thus the sign of $\rho_{\mathrm{NY}}\left(=\partial \rho_{\mathrm{V}} / \partial \sigma_{\mathrm{V}}=\partial \rho_{\mathrm{V}} / \partial \sigma_{\mathrm{Y}}\right)$ is also positive. These two. $\rho_{\mathrm{xz}}>0$ and $\rho_{\mathrm{N}}>0$, are necessary conditions for the stepwise aminolysis with rate-limiting breakdown of $\mathrm{T}=6 \mathrm{~b} .13 \mathrm{~s} . \mathrm{2} 7$

Now let us examine the mechanism of phenacyl transfers. Frontier molecular orbital (FMO) theory predicts that the lowest unoccupied antibonding orbital (LUMO) is the most likely orbital that is attacked by an incoming nucleophile in the nucleophilic substitution reactions. Among the two ty'pes of LUMOs. $\pi^{*} \mathrm{C}=0$ and $\sigma^{*} \mathrm{C} \cdot \mathrm{L} z{ }^{175}$ in the phenacyl derivatives. the former $\left(\pi^{*}(c=0)\right.$ is much lower than the latter $\left(\sigma^{*} \mathrm{C} \cdot \mathrm{L} z\right)$. This means that interaction of lone pair orbital $\left(n_{\Lambda}\right)$ on the nitrogen atom of the amine nucleophile is much stronger with $\pi^{*} \mathrm{C}=0$ and forms an intermediate. $\mathrm{T}^{ \pm}$. rather than with $\sigma^{*} \mathrm{CLZ}$ leading to a concerted $\left(\mathrm{S}_{\mathrm{N}} 2\right)$ displacement at the $\alpha$ carbon. ${ }^{17 \mathrm{~b}}$ It has been shown that due to the wide energy gap. $\Delta \varepsilon=\varepsilon_{\sigma^{*}}-\varepsilon_{\pi^{*}}$, the proclivity for the stable carbonyl addition intermediate formation is much stronger than the concerted $\mathrm{S}_{\mathrm{N}} 2$ displacement in the nucleophilic substitution of carbonyl compounds. ${ }^{\text {tho }}$ This means that in the aminolysis of phenacyl derivatives. a prior addition of the nucleophile to form a zwitterionic tetrahedral intermediate. $\mathrm{T}^{ \pm}(\mathbf{2})$. should occur. In fact a biphasic Brönsted plot is obtained in the pyridinolysis of phenacyl bromides ${ }^{i a}$ in $\mathrm{MeCN}$ indicating that a change in the rate-limiting step from breakdown to formation of $\mathrm{T}^{-}$occurs as the basicity of pyridine nucleophile increases. Once an addition intermediate (2) is formed. the leaving group (LZ) is expelled in the rate-determining step. In this step. the TS is formed by bridging of the amine between the carbonyl and $\alpha$-carbons. ${ }^{\text {th }}$

This unified mechanism. $\mathbf{1}+\mathbf{2}$. differs from the stepwise carbonyl transfer mechanisn. eq. 5 , in the rate-limiting expulsion. $k_{\mathrm{b}}$. the leaving group is expelled by the amine which bridges over the two carbon centers. $\alpha$-and carbonyl carbons. 6. In this TS structure (6) for the leaving group expulsion step. $k_{\mathrm{b}}$. the susceptibility of rate $\left(\mathrm{d} \log k_{\mathrm{b}}\right)$ to the<smiles>[R1]C1([O])[Te]C1[Te]</smiles>

basicity of amine ( $\mathrm{dp} K \mathrm{x}$ ), i.e., $\beta_{\mathrm{b}}$, should be insignificant $\left(\beta_{\mathrm{t}}\right.$ $\equiv 0$ ) since the two effects of $\mathrm{pK}$. (one. on the carbonyl carbon and the other. on the $\alpha$-carbon) will be compensatory or cancels out each other. In the former. electrons are transferred to the amine from the carbonyl carbon. whereas in the latter electrons are transferred from the amine to the $\alpha$ carbon. As a result the effect of amine on the stability of TS 6 will become negligible. In fact only a meager change in $\rho_{2}$ $\left(\Delta \rho_{Z}=0.05\right.$ ) was observed for the $\mathrm{p} K_{\mathrm{a}}(\mathrm{X})$ change of 0.36 (4$\mathrm{OMe} \rightarrow 4-\mathrm{Cl}$ benzylamine) in the aminolysis of phenacyl benzenesulfonates with benzy lamines in $\mathrm{MeOH}^{10}$ for $\mathrm{Y}=4$ $\mathrm{NO}_{2}$ at $45.0^{\circ} \mathrm{C}$. in contrast to a large change in $\rho_{Z}\left(\Delta \rho_{Z}=\right.$ 1.21) for the aminolysis of $\mathrm{C}_{2} \mathrm{H}_{5} \mathrm{C}(=\mathrm{O}) \mathrm{SC}_{6} \mathrm{H}_{5}$ with benzylamines $\left(\Delta \mathrm{p} K_{a}(\mathrm{X})=0.36\right)$ in $\mathrm{MeCN}$ at $45.0^{\circ} \mathrm{C}$. ${ }^{2 \mathrm{~b}}$ This means that in the phenacyl transfers. the overall $\beta_{\mathrm{X}}$ will be grossly independent of the amine nature and hence the $\beta_{\mathrm{X}}$ value becomes practically constant. eq. 9. i.e.. $\beta_{\mathrm{X}} \cong 0.7$ irrespective of the amine leaving group. or solvent. as experimentally observed (vide supra).

$$
\begin{aligned}
\beta_{\mathrm{x}} \cong \beta_{\mathrm{a}}-\beta_{\mathrm{a}} & \cong \text { constant }\left(\beta_{b} \cong 0\right) \\
& \cong 0.7
\end{aligned}
$$

The relative constancy of the $\beta$ : value therefore provides evidence for our unified mechanism $(1+2)$ of phenacyl transfers. As noted above, other pieces of evidence for the unified mechanism are (i) the sign of cross-interaction constants. $\rho_{\mathrm{XY}}>0 . \rho_{\mathrm{Y} z}>0$ (and $\rho_{\mathrm{Y} z}<0$ ), ${ }^{25}$ which are exactly opposite to those for the concerted $\left(\mathrm{S}_{\mathrm{N}} 2\right)$ type reactions ( $\rho \mathrm{xy}$ $<0, \rho_{\mathrm{YZ}}>0$ and $\rho_{\mathrm{XZ}}<0$ ). ${ }^{8}$ and (ii) adherence to the RSP. ${ }^{7 \mathrm{z} 26}$

The kinetic isotope effects $\left(k_{\mathrm{H}} / k_{\mathrm{D}}\right)$ involving deuterated benzylamines $\left(\mathrm{XC}_{6} \mathrm{H}_{4} \mathrm{CH}_{2} \mathrm{ND}_{2}\right)$ in Table 2 reveal that the $k_{\mathrm{H}} / k_{\mathrm{D}}$ values are all near unity. This is in accord with the 
Table 2. Kinetic isotope effects on the second-order rate constants $\left(k_{N}\right)$ for the reactions of Y-phenacyl bromides with deuterated $\mathrm{X}$ benzylamines $\left(\mathrm{XC}_{0} \mathrm{H}_{4} \mathrm{CH}_{2} \mathrm{ND}_{2}\right)$ in acetonitrile at $25^{\circ} \mathrm{C}$

\begin{tabular}{ccccc}
\hline $\mathrm{X}$ & $\mathrm{Y}$ & $k_{\mathrm{H}}\left(10^{-2} \mathrm{M}^{-1} \mathrm{~s}^{-1}\right)$ & $k_{\mathrm{D}}\left(10^{-2} \mathrm{M}^{-1} \mathrm{~s}^{-1}\right)$ & $k_{\mathrm{H}} / k_{\mathrm{I}}$ \\
\hline $\mathrm{H}$ & $4-\mathrm{OMe}$ & 6.76 & 6.58 & 1.03 \\
$\mathrm{H}$ & $\mathrm{H}$ & 8.71 & 8.58 & 1.02 \\
$\mathrm{H}$ & $3-\mathrm{NO}=$ & 19.1 & 18.5 & 1.03 \\
$4-\mathrm{Cl}$ & $4-\mathrm{OMe}$ & 4.20 & 4.01 & 1.05 \\
$4-\mathrm{Cl}$ & $\mathrm{H}$ & 5.62 & 5.20 & 1.08 \\
$4-\mathrm{Cl}$ & 3-NO2 & 12.0 & 11.0 & 1.09 \\
\hline
\end{tabular}

stepwise mechanism with rate-limiting breakdown of the intermediate. ${ }^{12.130 .28}$ As noted above. in the two TSs corresponding to the reversible steps $\left(k_{\mathrm{a}}+k_{-\mathrm{a}}\right)$ and the $k_{\mathrm{b}}$ step the effects of TS structure on $\mathrm{N}-\mathrm{H}(\mathrm{N}-\mathrm{D})$ vibrations will be compensatory and hence will be small.

The activation parameters. $\Delta H^{x}$ and $\Delta S^{\mp}$. summarized in Table 3 show that the activation enthalpies are relatively low and the entropies of activation have small negative values. Characteristically. they are rather insensitive to the variation of substituents in the nucleophile. $\mathrm{X}$. and in the substrate. $\mathrm{Y}$. This should result from the relatively loose TSs as indicated by a small cross-interaction constant. $\rho_{\mathrm{YY}}(=0.05)$, albeit the intervening groups in the nucleophile $\left(-\mathrm{CH}_{2}-\right)$ and in the substrate $(-\mathrm{C}(=\mathrm{O})$-) should make the distance from $\mathrm{X}$ and $\mathrm{Y}$ to the reaction center $(\alpha$-carbon) far apart and lead to fall-off of both substituent effects on the rate.

Another notable feature is the relatively small $-\Delta S^{\mp}$ values $\left(\Delta S^{\mp} \approx-10 \mathrm{eu}\right)$ which are in contrast to much larger negative

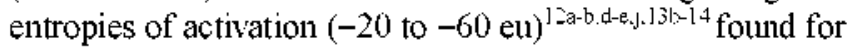
other aminolysis of esters in which the breakdown of $\mathrm{T}^{=}$is rate-limiting. Inspection of the TS structure (6) reveals that partial cleavage of $\mathrm{C}-\mathrm{N}^{-}$and $\mathrm{C}-\mathrm{LZ}$ bonds in the phenacyl transfer gives a relatively loose structure in contrast to partial bond cleavage of $\mathrm{C}-\mathrm{LZ}$ alone in the carbonyl transfers ( $5 \mathrm{a}$ or 5b).

Table 3. Activation parameters ${ }^{\pi}$ for the reactions of Y-phenacyl bromides with $\mathrm{X}$-benzylannines in acetonitrile

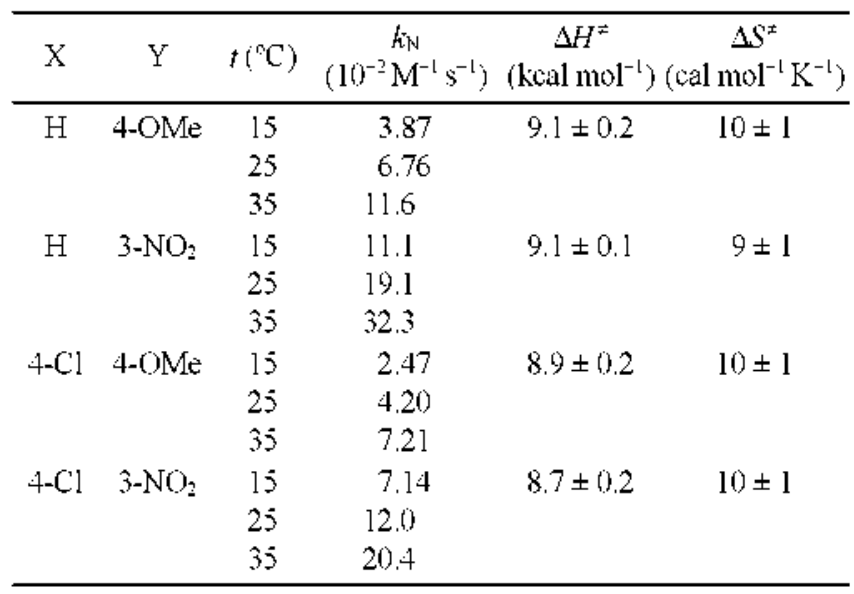

"Calculated by the Eyring equation. The maximum errors calculated (by the method of Wiberg. K. B. Ptysical Organic Chemstry. Wiley: New York 1964: p 378) are $=0.5 \mathrm{kcal} \mathrm{mol}^{-1}$ and \pm 2 eu for $\Delta H^{\neq}$and $\Delta S^{\mp}$. respectively.
Finally an alternative reaction path through an epoxide type TS. eq. 10. may be envisaged. However this path with TS $_{\text {epox }}$ is not consistent with the experimental results:

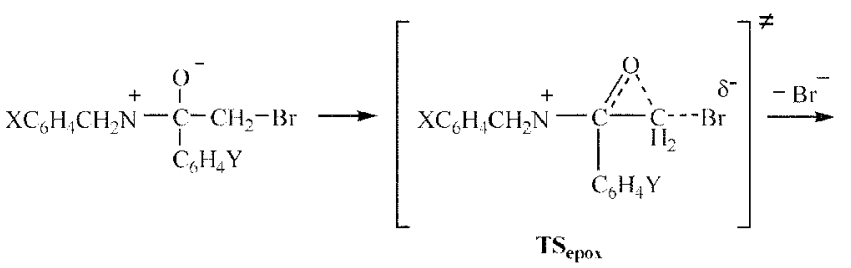

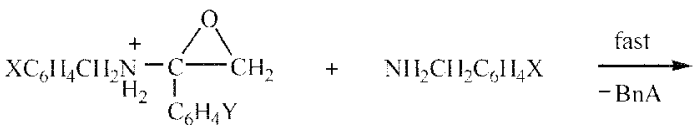

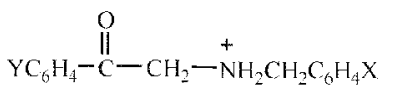

Firstly in the $\mathrm{TS}_{\text {epox }}$ the $-\mathrm{NH}_{2}\left(-\mathrm{ND}_{2}\right)$ moiety becomes more crowded than in $\mathrm{T}^{ \pm}$so that (i) $k_{\mathrm{H}} / k_{\mathrm{D}}$ should be less than one $e^{-9}$ in contrast to the observed values of $k_{\mathrm{H}} / k_{\mathrm{D}}=1.0$ and (ii) the $-\Delta S^{ \pm}$value should have been much larger $\left(\Delta S^{ \pm} \approx-20\right.$ to $-60 \mathrm{eu}$ ). Secondly. the $\beta_{\mathrm{b}}$ cannot be insignificantly small and independent of the amine nature (Table 2) since the expulsion rate of the leaving group. $\mathrm{Br}^{-}$, depends on push (or pull) provided by the amine in $\mathrm{T}^{=}$. This means that the $\beta_{\mathrm{X}}$ values $\left(=\beta_{4}-\beta_{-\mathrm{a}}+\beta_{6}\right)$ should differ depending on the amine nature as we found with the aminoly sis of esters ${ }^{12-14}$ Lastly in order to break the $\mathrm{CH}_{2}-\mathrm{Br}$ bond in $\mathrm{TS}_{\text {epox }}$ there should be substantial proxinate charge transfer from oxygen lone pairs

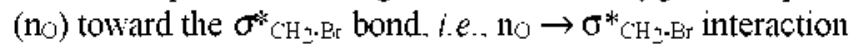
should occur. However this is rather difficult since $\sigma^{*} \mathrm{CH}_{2} \cdot \mathrm{Br}$ orbital is neither vicinal nor geminal to the oxygen lone pair (see Figure 2) so that the overlap between the two orbitals is very small. ${ }^{18.19}$ The no $\rightarrow \sigma^{*} \mathrm{CH}_{-}$-Br interaction should therefore be very weak and hence the $\mathrm{TS}_{\mathrm{epox}}$ should form a rather high barrier. i.e. the activation energy for the process (eq 10) should be much higher than the path through the amide bridge TS (in the form of 6 ). In this TS ( 6 with $\mathrm{LZ}=\mathrm{Br}$. NX $=\mathrm{BnA}$. and $\left.\mathrm{RY}=\mathrm{C}_{6} \mathrm{H}_{4} \mathrm{Y}\right)$ the strong $\mathrm{n}_{0} \rightarrow \sigma^{*} \mathrm{C}_{-}-\mathrm{K}^{+} \mathrm{X}$ vicinal charge transfer interaction facilitate $\mathrm{C}-\mathrm{N}^{-}$bond nupture so that the bridge formation becomes much easier.

\section{Experimental Section}

Materials. GR grade phenacyl bromides and benzylamines were used after recry'stallization. HPLC grade MeCN (water content is less than $0.005 \%$ ) was used without further purification, except drying over molecular sieve. storing under nitrogen atmosphere. and then distilled before use.

Kinetic Measurement. Rates were measured conductometrically at $25.0^{\circ} \mathrm{C}$ for the reactions of phenacyl bromides with benzylamines in $\mathrm{MeCN}$ using a computer controlled conductivity bridge constructed in this laboratory. Pseudofirst-order rate constants. kobsd. were measured by using curve fitting method in ORIGIN program (version 5.1). Pseudo-first-order rate constants were determined with large 
excess of nucleophiles. [substrate] $=1 \times 10^{3} \mathrm{M}$ and [nucleophile $]=0.1-0.5 \mathrm{M}$. Pseudo-first-order rate constant values were average of two (or three) nuns which were reproducible to $\pm 3 \%$.

Product Analysis. 4-Methoxy phenacyl bromide (0.15 M) was reacted with an exess of benzylamine $(3 \mathrm{M}$ ) for $24 \mathrm{hr}$ at $25^{\circ} \mathrm{C}$ in $\mathrm{MeCN}$. The product mixture was treated for workup with ether and water. The product mixture was separated by column chromatography (silica gel. $10 \% \mathrm{MeOH} / \mathrm{MC}$ ). Analysis of the product gave the following results

${ }_{4}-\mathrm{CH}_{3} \mathrm{OC}_{6} \mathrm{H}_{4} \mathrm{COCH}_{2} \mathrm{NHCH}_{2} \mathrm{C}_{6} \mathrm{H}_{5}$. liquid: Anal. Found: C. 75.4: $\mathrm{H}, 6.6: \mathrm{N}$. 5.3. Calcd for $\mathrm{C}_{16} \mathrm{H}_{17} \mathrm{NO}_{2}:$ C. 75.27: $\mathrm{H}$. 6.71: N. 5.49. $\delta_{\mathrm{H}}$. NMR $\left(200 \mathrm{MHz}, \mathrm{CDCl}_{3}\right) .7 .93-6.91(9 \mathrm{H}$. m. aromatic). 4.08 (2H. s. CH2). 3.89 (2H. s. CH2). 3.87 $\left(3 \mathrm{H} . \mathrm{s} . \mathrm{OCH}_{3}\right.$ ). 1.22 (1H. s. NH): MS (EI) $m z 255(\mathrm{M}+$ ).

Acknowledgement. This work was supported by INHA UNIVERSITY Research Grant (INHA-30395).

\section{References}

1. (a) Dewar. M. I. S. The Electronic Theory of Orgatic Chemism: Oxford University Press: Oxford. 1949; 73 . (b) McLennan. D. J.: Pross. A. J. Chem. Soc. Perhin Trans. 2 1984. 981 . (c) Pross. A.: Aviram. K: Klix. R. C.: Kost. D.: Bach. R. D. New: J. Chem. 1984. 8.7II. (d) Shaik. S. S. J Am. Chem. Soc. 1983. 105. 4359. (e) Pross. A.: De Frees. D. J.: Levi. B. A.: Pollack. S. K.: Radom, L.: Hehre, W. I. J. Org Chem 1981. t6. 1693. (f) Kost. D: Aviram. K. Tetrahedron Lett. 1982, 23, 4157. (g) Wolfe, S.: Mitchell. D. J.: Schlegel. H. B. Cam. J. Chem. 1982, 60. 1291.

2. (a) Conant. J. B.: Kirner. W. R. J. Am. Chem. Soc. 1924, 46. 232. (b) Ross. S. D.: Finkelstein. M.: Petersen. R. C. J Am. Chem. Soc. 1968, 90,6411 . (c) Halworsen, A.: Songstad. J. J. Chem. Soc., Chem. Conmun 1978, 327. (d) Bartlett, P. D: Trachtenberg. E. N. J. Am. Chem. Soc. 1958. 80. 15808. (e) Thorpe. J. W. Warkentin. J. Can. J. Chem. 1973. 51. 927. (t) Bordwell. F. G.: Brannen. W. T. J. Am. Chem. Soc 1964.86.4645.

3. (a) Bunton. C. A. Nicleophilic Substitution at a Saturated Catbon Atom: Elsevier: London, 1963: p 35. (b) Winstein. S: Grunwald, E.: Jones. H. W. J. Ant Chent. Soc. 1951. 73. 2700 .

4. Streitwieser. A.. J. Solvolvtic Displacement Reactions; MoGrawHill: New York. 1962.

5. (a) Yousaf. T. I.: Lewis. E. S. J. Am. Ghem. Soc. 1987. 109.6137. (b) Forster. W. Laird. R. M. J. Chem. Soc. Perkin Trans. 21982. 135 .

6. (a) Koh, H. J: Han, K. L.: Lee. H. W: Lee, I. J. Org Chent 2000, 65. 4706. (b) Lee. K. S.: Adhikar: K. K: Lee. H. W. Lee. B.-S.: Lee. I. Org. Biomol. Chem. 2003, 1. 1989.

7. (a) Lee. I. Bull. Korem (Chem. Soc. 1994. 15.985. (b) Lee. I.: Lee. H. W. Collect Czech. Chem. Commm. 1999. 64. 1529. (c) Yew. K. H.: Koh. H. J: Lee. H. W.: Lee, I. J. Chent. Soc. Perhin Trans. 21995.2263

8. Lee, I.Ad, Plns. Org. Chem 1992, 27. 57.

9. (a) Lee. I.: Kim. C. K.: Han. I. S.: Lee. H. W: Kim. W. K.: Kim. Y. B. J. Phns. Chem. B 1999, 103. 7302. (b) Coetzee. J. F. Prog. Phos. Org Chem 1965 t. 45

10. Lee, I.: Shim. C. S.: Lee, H. W. J. Phns Org Chent 1989. 2. 484

11. Lee, I.: Shim, C. S: Chung. S. Y.: Lee, H. W. J. Chem Soc.
Perkin Trams. 21988.975.

12. (a) Oh. H. K: Yang, J. H.: Lee. I. Bull Koram Chem. Soc 1999. 20. 1418 (b) Oh. H. K.: Yang. I. H.: Cho. I. H.: Lee. H. W.: Lee. I Int. J. Chem. Kinet 2000. 32. 485. (c) Lee. I.: Koh. H. J. Kew J. Chent 1996. 20. 131. (d) Oh. H. K: Kim. S. K.: Lee. I. Bull. Korean Chem. Soc. 1999. 20. 1017. (e) Koh, H.: Lee. J.W. Lee. H. W. Lee, I. New J. Chem. 1997. 21, 447, (f) Oh, H. K: Lee, J. Y.: Lee. I. Bull. Korean Chem. Soc, 1998, 19, 1198 . (g) Oh, H. K; Woo. S. Y.: Shin. C. H.: Lee. I. Int. J. Chem. Kinet 1998. 30. 849. (h) Oh. H. K.: Kim. S. K: Lee. H. W: Lee. I. Yew J. Chom 2001. 25.313. (i) Oh. H. K.: Kinn. S. K.: Cho. I. H.: Lee. H. W.: Lee. I. $J$. Chent. Sac. Perkin Trans. 22000.2306

13. (a) Oh. H. K: Woo. S. Y.: Shin C. H.: Park. Y. S.; Lee, I. J. Org. Chem 1997, 62. 5780. (b) Oh. H. K.: Kim. S. K. Lee, H. W: Lee I. J. Chem Soc. Perkin Trans. 2 2001. 1753 (c) Oh. H. K.: Shit1. C. H.: Lee. I. J. Chem. Soc. Porhin Trans. 21995.1169.

14. (a) Oh. H. K: Ku. M. H.: Lee. H. W. Lee. I. J. Org. Chent 2002. 67. 3874. (b) Koh. H. J.: Han, K. L.; Lee. I. J. Org Chem. 1999. 64. 4783. (c) Oh, H. K; Ku, M. H; Lee. H. W.: Lee. I. J. Org. Chem. 2002, 67,8995.

15. Gresser. M. I.: Jencks. W. P. J. Am. Chom. Soc. 1977. 99.6970.

16. Pross. A. Theoretical and Physical Principles of Organic Reactivity: Wiley: New York. 1995: Chapter 8.

17. (a) Fleming, I. Frontier Orbitals and Organic Chentical Reactions: Wiley: London, 1976. (b) Lee, I; Kim, C. K, Li, H. G.; Sohn, C. K.; Kim. C. K.: Lee. B.-S. J. Am. Chem Soc. 2000. 122. 11162

18. Epiotis. N. D.: Cherry. W. R.: Shaik. S.: Yates. R.: Bernardi. F. Structwal Theory of Organic Chentistry. Springer-Verlag: Berlin. 1977.

19. (a) Reed. A. E.: Curtiss. L. A.; Weinhold. F. Chent Ren: 1988. 88. 899. (b) Brunck, T. K.: Weinhold, F. J. Am. Chem. Soc. 1979, 101. 1700 .

20. (a) Deslongchamps. P. Stemoelectronic Effects in Organic Chentistry. Pergamon Press: Oxford. 1983. (b) Kirby. A. T. The Anonteric Effect and Retated Stereotectronic Effects at Ongent. Springer-Verlag: Berlin. 1983. (c) Page. I.: Williams, A. Conerted Organic and Bio-Organic Mfechanisms: CRC Press: Boca Raton. 2000): p 11 l. (d) Page. I.: Williams. A. Organic and Bio-Organic Mechanisms: Longman: Harlow. 1977: $\mathrm{p} 42$.

21. Hammond. G. S. J.Am. Chem. Soc. 1955. 77.334

22. (a) Ref. 28 , Chapter 5. (b) Dewar. M. J. S.; Doughert: R. C. The PHO Theory of Organic Chentisny, Plenum: New York. 1975; Chapter 5.

23. (a) Pross. A. Adv Phus. Ong Chem. 1977. 14.69. (b) Buncel. E.: Wilson. H. J. Chem. Educ. 1987. 64. 475.

24. Klumpp. G. W. Reactinin in Organic Chemism: Wiley: New York, 1982; $\mathrm{p} 310$.

25. Note that $\beta_{0}$ is different from $\beta_{\mathcal{Z}}\left(=\beta_{y}\right.$ ) which is negative and represents the susceptibility of the overall rate $(\log h)$ to the change in $p K_{a}$ values of the leaving group (Z).

26. Lee. I.: Lee. B.-S.: Koh. H. J.: Chang. B. D. Bull. Kowan Chem Soc. 1995. 16.277.

27. (a) Lee, I. Bull Korem Chem. Soc. 1994, 15. 985. (b) Kim, T.-H.: Huh. C.; Lee. B.-S.; Lee. I. J. Chem. Soc. Perkin Trans. 21995. 2257. (c) Koh. H. J.: Kim. O. S: Lee, H. W. Lee. I. J. Phus. Org. Chem. 1997. 10. 725. (d) Koh. H. T.: Han. K. L.: Lee. H. W.: Lee. I. J. Org. Chem. 1998. 63. 9834.

28. (a) Lee. I.: Koh. H. T. New J. Chem. 1996. 20. 131. (b) Koh. H. J. Lee. H. C.: Lee, H. W.; Lee. I. Bull. Korean Chent Soc. 1995. 16. 839 .

29. Lee. I. Chem. Soc. Rev $1994,24,223$. 